Table 1. Current Treatment Information of the Patients

\begin{tabular}{lr}
\hline Current Treatment Information & \\
\hline DMARD & 26 \\
Colchicine & 23 \\
Adalimumab & 21 \\
Etanercept & 10 \\
NSAID & 4 \\
Tocilizumab & 3 \\
Cyclophosphamide & 3 \\
Rituximab & 2 \\
Prednisolone & 7 \\
Mycophenolate Mofetil & 1 \\
Canakinumab & 1 \\
\hline
\end{tabular}

Seven patients had FMF related attacks. In addition to attacks, one FMF patient had bilateral ankle pain and one patient had leg pain. One patient out of three diagnosed with Takayasu's disease was still symptomatic. One patient had uveitis-related symptoms. One patient diagnosed with SLE had skin dryness. Furthermore, there were patients with sequelae formation. One patient diagnosed with oligoarticular JIA (OJIA) had bilateral hip sequela with the additional left hip prosthesis. One oJIA patient had micrognathia, and one had left knee sequela. One pJIA patient had small joint sequelae. One sJlA patient had bilateral hip sequelae. One jSPA patient had enthesopathy. One FMF patient had proteinuria due to amyloidosis formation. Another FMF patient had hip surgery due to sequela.

Conclusion: Our center had patients with a variety of conditions with different natures of diseases. EULAR recommends the transition process to start no later than 14 years of age; however, this process started at the mean age of 21 in our patients. In most of these patients, especially the ones diagnosed with FMF, the control of disease activity was maintained. The transition of these different clinical entities might require certain amendments to the standard of care. For future references, we will be able to understand more about the adulthood prognosis of these clinical entities.

Disclosure of Interests: None declared

DOI: 10.1136/annrheumdis-2020-eular.3436

\section{AB1326-HPR TOBACCO ADDICTION IN PEOPLE WITH RHEUMATOID ARTHRITIS - FROM THE PERSPECTIVE OF PATIENTS}

B. A. Esbensen ${ }^{1,2}$, I. K. Roelsgaard ${ }^{1}$, S. K. Larsen ${ }^{1}$, T. Thomsen ${ }^{2,3}$

${ }^{1}$ Copenhagen Center for Arthritis Research (COPECARE), Center for

Rheumatology and Spine Diseases, Glostrup, Denmark; ${ }^{2}$ University of

Copenhagen, Department of Clinical Medicine, Copenhagen, Denmark; ${ }^{3} \mathrm{Herlev}$ and Gentofte Hospital, Copenhagen, Herlev Acute, Critical and Emergency

Care Science Unit, Department of Anaesthesiology, Herlev, Denmark

Background: Smoking is one of the most significant modifiable exosomes risk factors for rheumatoid arthritis (RA) (1). Studies suggest that $25-30 \%$ of people with RA in Denmark smoke (2). This is almost twice as many as in the background population in Denmark. People with RA have a significant increased risk of severe comorbidity including cardiovascular disease. In addition, there are indications that smokers with RA have a poorer effect of the medical inflammatory treatment compared to non-smokers, and consequently more difficult to achieve remission of the disease activity (3). Tobacco addiction is complex and can be a challenge in smoking cessation. In addition to physiological dependence, habits and social and environmental factors may influence addiction. Tobacco smoking is associated with an addiction to nicotine and it is unexplored how this addiction appears in people with RA.

Objectives: The aim of this study was to examine from the patient's perspective how tobacco addiction appears in people with rheumatoid arthritis.

Methods: We conducted a qualitative study based on a hermeneutics approach. People with RA who previously had participated in a randomized controlled study (4) about smoking cessation conducted at the Center for Rheumatology and Spine Diseases at Rigshospitalet, Denmark were recruited for semi-structured interviews.

Results: In total, 12 people with RA (50\% female) were included in the study. The median age was 62 years and median RA disease duration was 12 years. The degree of physical dependence measured by Fagerströms Test for Nicotine dependence (FTND) was on average: 4.9 (score: 0-10, 0=nonphysical dependence).

Three categories of how tobacco addiction appeared emerged during the analysis: 1) It develops into ingrown habits referring to the fact that smoking already in adolescence contributes to the development of specific physical, mental and social smoking behavior. Not all individuals considered themselves addicted to nicotine as they did not necessarily connect the nicotine to the ingrown habits. 2) The body craves for nicotine referring to nicotine proved calming, while a lacking or insufficient dose caused withdrawal symptoms. Furthermore, smoking became a habit where a craving for smoking occurred in certain situations. 3)
Ambivalence - for and against referring to the physical dependence and smoking habits making a smoking cessation difficult. Dependency to nicotine and challenges to quit smoking led to a feeling of ambivalence and a lack of control. Conclusion: Tobacco addiction appeared as a physical dependence and a habit, which, during a smoking cessation, led to ambivalent feelings. Therefore, based on this study, there is still a need for health professionals to talk to patients about smoking. But also, a need to articulate the complexity of addiction in order to support for smoking cessations. Information should be strengthened in the clinical practice in relation to nicotine's implication in tobacco addiction as well as the consequences of tobacco smoking for individuals with RA.

References:

[1] Scott DL, Wolfe F, Huizinga TW. Lancet. 2010 \#\#\#

[2] Loppenthin K, Esbensen BA, Jennum P, Ostergaard M, Tolver A, Thomsen T, et al. Clin Rheumatol. 2015. \#\#\#

[3] Roelsgaard IK, Ikdahl E, Rollefstad S, Wibetoe G, Esbensen BA, Kitas GD et al. Rheumatology (Oxford). 2019. \#\#\#

[4] Roelsgaard IK, Thomsen T, Ostergaard M, Christensen R, Hetland ML, Jacobsen S, et al. Trials. 2017;18(1):570.\#\#\#

Disclosure of Interests: None declared

DOI: 10.1136/annrheumdis-2020-eular.965

\section{AB1327-HPR SELF-ASSESSMENT OF ORAL HEALTH STATUS IN RHEUMATOID ARTHRITIS, SYSTEMIC LUPUS ERYTHEMATOSUS AND CONTROLS}

C. M. Gamboa-Alonso ${ }^{1}$, J. D. Ángulo ${ }^{1}$, M. J. Garza Martínez ${ }^{1}$, G. FigueroaParra $^{1}$, A. L. De-Leon-Ibarra ${ }^{1}$, J. C. Riegatorres ${ }^{1}$, D. Á. Galarza-Delgado'. ${ }^{1}$ Hospital Universitario José Eleuterio González, Rheumatology, Monterrey, Mexico

Background: Different periodontal disorders have been associated with the development of multiple rheumatic diseases, encouraging the production of citrullinated proteins and creating a proinflammatory state with an increase in oral and systemic symptomatology.

The Geriatric/General Oral Health Assessment Index (GOHAI) survey has been used as a self-assessment tool where studies have found a diminished quality of oral health in Rheumatoid Arthritis (RA). ${ }^{1}$

Objectives: Compare the behavior of GOHAl survey in RA, Systemic lupus erythematosus (SLE), and controls in a Rheumatology center at Northeast Mexico.

Methods: We performed a descriptive study of patients with RA and LES who answered the Spanish version of GOHAI survey. A control group was also included.

GOHAI survey consists of 12 Questions with Likert answers evaluating problems related to periodontal disease in the last 3 months.

Questions 1-4 evaluate physical function, 6, 7, 9-11 psychosocial status and 5, 8 and 12 pain.

Results: Sixty RA patients, 32 SLE patients and 46 controls were included. Groups were adjusted by sex and age.

GOHAl survey presented a total mean of 23.4 in RA, 22.06 in SLE and 21.54 in controls with a maximum score of 60 points.

When analyzing the survey in physical function and psychosocial status a statistical significant difference was found when comparing RA group to controls.

Table 1. Comparison between GOHAl index scores in RA, SLE and control groups

\begin{tabular}{|c|c|c|c|c|}
\hline & RA $n=60$ & SLE $n=32$ & $\begin{array}{c}\text { Controls } \\
n=46\end{array}$ & \\
\hline & Median (SD) & Median (SD) & Median (SD) & $\begin{array}{l}\text { RA vs RA and Three } \\
\text { SLE controls groups }\end{array}$ \\
\hline Age & $51.27(15.84)$ & $37.03(14.14)$ & $41.07(11.25)$ & 0.17 \\
\hline Sex & $58(96.67 \%)$ & $29(90.62 \%)$ & $42(91.3 \%)$ & \\
\hline $\begin{array}{l}\text { 1. Limit the kinds of food } \\
\text { consumed }\end{array}$ & $1.87(1.14)$ & $1.78(1.15)$ & $1.78(0.81)$ & \\
\hline $\begin{array}{l}\text { 2. Trouble biting or } \\
\text { chewing }\end{array}$ & $1.96(1.2)$ & $1.91(1.27)$ & $1.78(1)$ & \\
\hline $\begin{array}{l}\text { 3. Able to swallow } \\
\text { comfortably }\end{array}$ & $2.2(1)$ & $1.81(1.47)$ & $1.41(1.15)$ & \\
\hline $\begin{array}{l}\text { 4. Unable to speak } \\
\text { clearly }\end{array}$ & $1.63(1)$ & $1.13(0.42)$ & $1.24(0.57)$ & \\
\hline $\begin{array}{l}\text { 5. Able to eat without } \\
\text { discomfort }\end{array}$ & $1.9(1.17)$ & $1.59(0.98)$ & $1.76(0.79)$ & \\
\hline $\begin{array}{l}\text { 6. Limit contact with } \\
\text { people }\end{array}$ & $1.45(0.9)$ & $1.34(0.75)$ & $1.3(0.73)$ & \\
\hline $\begin{array}{l}\text { 7. Pleased with appear- } \\
\text { ance of teeth }\end{array}$ & 2.85 (1.65) & $3.2(1.79)$ & $2.22(1.25)$ & \\
\hline 8. Use medication to & $1.83(1.08)$ & $1.94(1.13)$ & $1.87(0.88)$ & \\
\hline
\end{tabular}

relieve pain 
Table 1. Comparison between GOHAl index scores in RA, SLE and control groups

\begin{tabular}{|c|c|c|c|c|c|c|}
\hline & RA $n=60$ & SLE $n=32$ & $\begin{array}{c}\text { Controls } \\
n=46\end{array}$ & & & \\
\hline & Median (SD) & Median (SD) & Median (SD) & $\begin{array}{l}\text { RA vs } \\
\text { SLE }\end{array}$ & $\begin{array}{l}\text { RA and } \\
\text { controls }\end{array}$ & $\begin{array}{l}\text { Three } \\
\text { groups }\end{array}$ \\
\hline $\begin{array}{l}\text { 9. Worried about teeth, } \\
\text { gum or dentures }\end{array}$ & $2.56(1.39)$ & $2.06(1.54)$ & $2.54(1.15)$ & & & \\
\hline $\begin{array}{l}\text { 10. Self-conscious about } \\
\text { teeth, gum or dentures }\end{array}$ & $1.66(0.94)$ & 1.59 (1.02) & $2.02(1.06)$ & & & \\
\hline $\begin{array}{l}\text { 11. Uncomfortable eating } \\
\text { in front of others }\end{array}$ & $1.54(0.82)$ & $1.53(0.8)$ & $1.39(0.8)$ & & & \\
\hline $\begin{array}{l}\text { 12. Sensitive to hot,cold } \\
\text { or sweet food }\end{array}$ & $2.07(1.06)$ & $2.19(1.31)$ & $2.22(0.94)$ & & & \\
\hline Total score $(12-60)$ & $23.4(6.94)$ & $22.06(7.05)$ & $21.54(5.6)$ & 0.27 & 0.12 & 0.19 \\
\hline Physical function & 7.6 (3.32) & $6.63(2.6)$ & $6.22(2.26)$ & 0.15 & 0.06 & 0.05 \\
\hline Psychosocial function & $10.07(3.23)$ & $9.72(3.74)$ & $9.48(3.5)$ & 0.35 & 0.003 & 0.02 \\
\hline Pain discomfort & $5.78(2.19)$ & $5.72(2.48)$ & $5.85(1.48)$ & 0.69 & 0.15 & 0.1 \\
\hline
\end{tabular}

RA: Rheumatoid Arthritis, SLE: Systemic Lupus Erythematosus

Conclusion: RA patients presented an increased alteration in oral health perspective when compared to SLE and controls. This association demonstrates the relationship between $R A$ and periodontitis pathogenesis.

Importance in diagnosing periodontal disorders in rheumatic diseases should be performed due to its influence in quality of life and perpetuation of an inflammatory state and oral symptoms.

References:

[1] Blaizot, A., Monsarrat, P., Constantin, A., Vergnes, J. N., de Grado, G. F., Nabet, C., ... \& Sixou, M. (2013). Oral health-related quality of life among outpatients with rheumatoid arthritis. International dental journal, 63(3), 145-153.

Disclosure of Interests: None declared

DOI: 10.1136/annrheumdis-2020-eular.5741

\section{AB1328-HPR INCREASED BODY MASS INDEX AFFECTS SPINAL MOBILITY RATHER THAN DISEASE ACTIVITY IN ANKYLOSING SPONDYLITIS}

M. He ${ }^{1}$, Y. Bao ${ }^{1}$, Y. Yang ${ }^{1}$, S. Liu ${ }^{1}$, C. Dong ${ }^{1}$, W. Zhou ${ }^{1}$, J. Guo ${ }^{1}$, J. Liu ${ }^{1}$, Y. Chen, Z. Gu ${ }^{1} .{ }^{1}$ Affiliated Hospital of Nantong University, Nantong, China

Background: Studies have reported the association between overweight or obesity and ankylosing spondylitis (AS), but their relation is still unclear in China. Objectives: To explore the prevalence of overweight or obesity and its effect on other indicators and their relationships in Chinese AS patients.

Methods: Demographic and clinical variables were collected from 207 AS patients. Patients were categorized to normal BMl group $\left(\mathrm{BMl}<23 \mathrm{~kg} / \mathrm{m}^{2}\right)$ and overweight group $\left(\mathrm{BMI} \geq 23 \mathrm{~kg} / \mathrm{m}^{2}\right)$. We used Bath Ankylosing Spondylitis Disease Activity Index (BASDAI), Bath Ankylosing Spondylitis Functional Index (BASFI), Bath Ankylosing Spondylitis Metrology Index (BASMI), Health Assessment Questionnaire (HAQ), Ankylosing Spondylitis Quality of Life (ASQoL) and Medical Outcomes Study Short Form 36 (SF36) to evaluate disease activity, physical function, spinal mobility, functional limitation and health-related quality of life, respectively. Statistical analysis used independent $t$ test, Mann-Whitney U test, Chi-square test and Spearman's rank correlation test. Results: $56.5 \%$ (117) AS patients were overweight or obese, among which $80.3 \%$ (94) were male. In the overweight group, patients were older, more being married, and have higher BMI, higher waist circumference, higher waist-to-hip ratio, longer disease duration, higher BASMI score, higher white blood cell count (WBC), higher lymphocyte and higher platelet count compared to the non-overweight group $(P \leq 0.038)$. However, there was no distinct difference in BASDAI score between the two groups $(P=0.891)$. In the correlation analyses, gender and marital status $(P \leq 0.036)$ were correlated negatively with $\mathrm{BMI}$; while age, waist circumference, waist-to-hip ratio, WBC, lymphocyte count and red blood cell $(P \leq 0.036)$ were correlated positively with BMI.

Conclusion: Overweight or obesity is common in Chinese AS patients. Increased BMI affects not disease activity but spinal mobility, which indicates that patients with high $\mathrm{BMI}$ are more likely to have limitations in flexion, extension, lateral bending and torsion of spine.

References:

[1] Bowness P. Hla-B27. Annu Rev Immunol. 2015;33:29-48.

[2] de Araújo TA, Mota MC, Crispim CA. Obesity and sleepiness in women with fibromyalgia. Rheumatology International. 2014;35(2):281-7.

Acknowledgments: This study was funded by Science and technology Project of Nantong City (Grant/Award Number: MSZ18217), Postgraduate Research \& Practice Innovation Program of Jiangsu Province (Grant/Award number: KYCX19_2071 and KYCX18 2410), National Natural Science Foundation of China (Grant/Award number: 81671616 and 81871278 ), Science and technology Project of Jiangsu Province (Grant/Award number: BE2018671) and Clinical Research Center of Stem Cells, Affiliated Hospital of Nantong University, Nantong (Grant/Award number: HS2018001).

Disclosure of Interests: None declared

DOI: 10.1136/annrheumdis-2020-eular.6213

\section{AB1329-HPR THE CURRENT STATUS AND ASSOCIATED FACTORS OF FATIGUE IN CHINESE PATIENTS WITH GOUT}

J. Guo ${ }^{1}$, W. Zhou ${ }^{1}$, M. He ${ }^{1}$, Z. Gu${ }^{1}$, C. Dong ${ }^{1} .{ }^{1}$ Affiliated Hospital of Nantong University, Nantong, China

Background: Fatigue of chronic diseases has been paid more and more attention. but the status of fatigue in gout patients has not been reported all the world[1].

Objectives: In the absence of previous studies, our study aims to investigate the fatigue status, explore the potential predictors of fatigue and the effects of fatigue on health-related quality of life (HRQoL) among Chinese gout patients.

Methods: This cross-sectional study was conducted from the Affiliated Hospital of Nantong University. A series of questionnaires were applied: Fatigue Scale-14 (FS-14), the $10 \mathrm{~cm}$ visual analog scale (VAS), the Patient Health Questionnaire (PHQ-9), the Generalized Anxiety Disorder questionnaire (GAD-7), the Pittsburgh Sleep Quality Index (PSQI), Health Assessment Questionnaire(HAQ), the Short Form 36 health survey (SF-36). Laboratory examinations were taken to obtain some biochemical indicators. Independent samples t-test, Mann-Whitney U-test, Chi-square analysis, Pearson /Spearman correlation, Stepwise linear regression and binary logistic regression were used to analyze the data.

Results: 411 gout patients were included in this study. Among them, more than $50 \%$ patients reported physical fatigue in FS-14, severe disease, poor psychological status and reduced HRQoL were associated with fatigue. Multiple stepwise linear regression and binary logistic regression were applied and showed that pain, sleep quality, anxiety, depression and functional disorder were the potential predictors of fatigue. In addition, we found that the more severe the fatigue, the lower the patient's HRQoL.

Conclusion: Fatigue among gout patients is exceedingly common. The results of this study suggested that rheumatologists should pay closely attention to gout patients who suffer from serious fatigue, especially those with pain, poorer sleep quality, anxiety, depression and functional disorder.

References:

[1] Henry, A., Tourbah, A., Camus, G., Deschamps, R., Mailhan, L., Castex, C. Gout, O. \& Montreuil, M. (2019) Anxiety and depression in patients with multiple sclerosis: The mediating effects of perceived social support, Multiple sclerosis and related disorders. 27, 46-51.

Disclosure of Interests: None declared

DOI: 10.1136/annrheumdis-2020-eular.6338

\section{AB1330-HPR ASSOCIATION OF INTERSTITIAL LUNG DISEASE AND QUALITY OF LIFE IN CHINESE RHEUMATOID ARTHRITIS}

Y. Wang ${ }^{1}$, R. Zhao ${ }^{1}$, C. Dong ${ }^{1}$, Z. Gu ${ }^{1} .{ }^{1}$ Affiliated Hospital of Nantong University, Nantong, China

Background: The health-related quality of life (HRQL) of patients with rheumatoid arthritis associated interstitial lung disease (RA-ILD) is less concerned(1) This study hypothesized that HRQL of such patients decreased.

Objectives: The aim of this study was to assess the difference in HRQL between RA with and without ILD, and to predict risk factors of HRQL in Chinese RA-ILD. Methods: A cross-sectional survey of RA-ILD patients included socio-demographic characteristics, clinical variables, psychological factors and HRQL. Data were analyzed by Student's t or chi-square test. Linear regression analysis was used to investigate the predictors of HRQL in RA-ILD.

Results: The data showed that $35.17 \%(51 / 145)$ of RA patients had ILD. There are significant differences in age, sex, smoking history, disease duration and activity between RA with and without ILD. HRQL of RA-ILD was impaired. Phys ical component score (PCS) of patients with RA-ILD was also worse than that of RA without ILD (48.91 \pm 2.48 vs. $50.80 \pm 2.55)$. Linear regression analysis showed that DAS28 and fatigue were risk factors for PCS in patients with RA-ILD, while depression and rural residence were risk factors for mental components summary in Table 1.

Table 1. Stepwise multiple linear regression analysis of PCS and MCS in RA-ILD

\begin{tabular}{lccccc}
\hline Predictors & B & SE & $\mathbf{t}$ & $P$ & $\mathbf{9 5 \%} \mathbf{C l}$ \\
\hline PCS & & & & & \\
DAS28 & -0.777 & 0.227 & -3.425 & 0.001 & $-1.236,-0.319$ \\
Fatigue & -0.655 & 0.206 & -3.177 & 0.003 & $-1.071,-0.238$ \\
MCS & & & & & \\
Depression & 2.188 & 0.669 & 3.272 & 0.002 & $0.836,3.539$ \\
Rural residents & -1.609 & 0.756 & -2.128 & 0.040 & $-3.137,-0.081$ \\
\end{tabular}

Footnotes: $\mathrm{Cl}=$ Confidence interval. $\mathrm{PCS}=$ Physical component score; MCS=Mental component score; DAS28=28-joint disease activity score. 